\title{
Elección de la carrera de Turismo: una mirada sociológica
}

\author{
Evangelina Cruz-Barba
}

\section{RESUMEN}

A partir de la propuesta teórica de Weber sobre tipos ideales, y de Elster con sus aportes para la comprensión de la racionalidad limitada del sujeto en los procesos de elección, este trabajo presenta la narrativa de cómo un grupo de docentes eligieron una profesión de reciente creación en la Universidad de Guadalajara, México, en la década de los años setenta. A partir de una metodología cualitativa, se argumenta que los sedimentos de las vivencias de los entrevistados continúan en su labor como docentes, proyectándose en la formación de las nuevas generaciones de licenciados en turismo.

Palabras clave: turismo, elecciones, educación superior, México.

\section{Escolha do curso de Turismo: um olhar sociológico}

\section{RESUMO}

A partir da proposta teórica de Weber sobre tipos ideais, e de Elster com suas exportações para a compreensão da racionalidade limitada do sujeito nos processos de escolha, este trabalho apresenta a narrativa de como um grupo de docentes escolheram uma profissão de recente criação na Universidad de Guadalajara, México, na década de setenta. A partir de uma metodologia qualitativa, se argumenta que os sedimentos das vivencias dos entrevistados continuam em seu labor como docentes, projetando-se na formação das novas gerações de licenciados em turismo.

Palavras chave: turismo, eleições, ensino superior, México.

\section{Choosing a Career in Tourism: a Sociological Perspective}

\section{ABSTRACT}

Based on Weber's theoretical proposal on ideal types and Elster's contributions to understanding the limited rationality of the subject in the election processes, this work presents the narrative of how a group of teachers chose a newly created profession at the University of Guadalajara, Mexico, in the 1970s. Based on a qualitative methodology, the author shows how the sediments of the experiences of the interviewees continue in their work as teachers, projecting themselves in the formation of new generations of Tourism graduates.

Key words: tourism training, elections, higher education, Mexico. 


\section{Introducción}

La demanda por educación superior se basa en la elección que realiza el estudiante al determinar por anticipado ciertos elementos que considera necesarios para insertarse en un mercado laboral futuro, así también se condiciona a gustos personales producto de un contexto de socialización donde se conjugan los siguientes elementos: un espacio geográfico, las pluralidades de sentido, el tiempo social, lo simbólico y las prácticas sociales como praxis donde se manifiestan los deseos, capacidades y posibilidades del ser humano, sus relaciones y conflictos (Lindon, 2004: 41).

Es importante resaltar que un factor determinante en la elección de la profesión es el contexto en que se desarrolla el sujeto. $\mathrm{Al}$ respecto, consideramos la postura de Cleaves (1985) bajo la lógica de que las profesiones responden a un mercado laboral que a su vez se determina por el cambio constante en los modos de producción y de las relaciones sociales, es decir en un espacio contextual bien definido.

En este sentido, identificamos que la motivación para elegir una profesión desde una perspectiva sociológica dista mucho de ser una elección racional de acuerdo con la teoría económica, porque la información que posee un individuo no le permite tener conocimiento pleno entre costos y beneficios al momento de elegir una profesión, lo que nos lleva a considerar la existencia de racionalidad limitada en el proceso de elección.

Aunque existe una vasta literatura soportada en la teoría del capital humano de Becker (1993) que abona al entendimiento de la elección de carrera desde una perspectiva económica, estos estudios no analizan la carrera de turismo, de ellos destacan los trabajos de Jiménez y Salas (1999) y de Higuera (2012). Desde el enfoque sociológico no existe, hasta nuestro conocimiento, literatura sobre elección de carrera en turismo. Aunque hay trabajos en México que analizan la carrera de Turismo, principalmente de la Universidad Autónoma del Estado de México (UAEM), éstos no abordan el problema de la elección de carrera. ${ }^{1}$

El caso particular que se aborda en este trabajo, sobre la licenciatura en Turismo en la Universidad de Guadalajara (UdeG), toma relevancia a partir de dos factores: la importancia de la actividad turística en la economía al participar aproximadamente con un $8.3 \%$ del Producto Interno Bruto (PIB) total nacional (Rodríguez y Támez, 2016), y la relevancia de la demanda de carrera en la UdeG. La licenciatura en Turismo en la UdeG es la segunda que surge en México, en 1968, con un currículum académico sujeto a particularidades históricas y contextuales de la actividad turística. Además, el comportamiento sobre la demanda de acuerdo con Chavoya (2003) refiere que las carreras de Contaduría, Derecho, Médico Cirujano y Partero, Administración y Turismo son las carreras con mayor demanda en la UdeG, dato que sigue vigente en lo que respecta a la profesión del turismo de acuerdo con la estadística de la Asociación Nacional de Universidades e Instituciones de Educación Superior (ANUIES, 2016), que indica que la UdeG ocupa los primeros lugares en matrícula de licenciatura en Turismo.

En virtud de lo anterior, el objetivo de este trabajo es identificar elementos sociológicos que develen el por qué se elige la carrera de Turismo. Sustentamos la investigación a partir de una metodología cualitativa porque el interés radica en "explorar la dinámica de las interacciones con énfasis en el mundo como una realidad socialmente construida que involucra diferentes perspectivas" (Campos, 2014: 12). Así, a partir de un conjunto de entrevistas a un grupo de docentes de la citada casa de estudios, y a través de un análisis del contexto que rodeaba la profesión de turismo, se identifica de manera diacrónica y sincrónica el proceso de elección.

\footnotetext{
${ }^{1}$ El trabajo refiere la representación social de que el título universitario de los estudiantes de Turismo de la UAEM les permitirá un mejor empleo, una mayor remuneración y estatus social.
} 
Ahora bien, para comprender el problema de elección ante una racionalidad limitada, utilizamos la perspectiva teórica de Max Weber y Jon Elster, ya que ambos comparten la idea de que existe una racionalidad limitada en la elección de los individuos. Por una parte, Elster (1999) hace énfasis en la percepción y los procesos cognitivos personales del individuo al momento de realizar una elección racional, y Weber (2008) considera que para poder superar el problema de la racionalidad limitada los individuos tienen que tener una referencia sobre qué quieren elegir y a dónde quieren ir con su elección, de tal manera que una referencia de "tipo ideal" permite no sólo considerar las percepciones individuales sino también el contexto macro en el que el individuo se desarrolla y elige.

Por tanto, en el siguiente apartado se hace una revisión de la perspectiva sobre la racionalidad limitada de Weber y Elster, así también se enfatiza en este marco teórico el proceso de la elección de carrera. En el tercer apartado se describe la estrategia metodológica. En el cuarto apartado se presenta el análisis de los resultados, para finalmente concluir.

\section{Max Weber y Jon Elster en la elección racional}

En principio, Weber (2008) aplica el concepto de elección racional desde el punto de vista sociológico con la concepción de que reconoce que los individuos son importantes en la elección. Los sujetos atribuyen sus significados a partir de su propia individualidad y experiencia como producto de una realidad empírica observable.

Para Weber en la acción social se expresa el proceso de elección racional y existe una distinción radical entre la indagación empírica de los hechos sociales y las valoraciones, por lo tanto realiza una diferencia entre la acción social que refiere a una racionalidad adaptada a medios y fines, y la acción social que implica una racionalidad de los valores. En este sentido, para Weber (2008) existen cuatro tipos de acción social, las cuales no son excluyentes: primero, la acción racional con arreglo a fines, donde el sujeto concibe con claridad su fin y elige de acuerdo con sus medios; segundo, acción racional con arreglo a valores, va de acuerdo con convicciones; tercero, acción afectiva, enfatiza su parte emocional, y cuarta, acción tradicional, vinculada a hábitos, costumbres y creencias.

Elster (1984) retoma del marxismo la noción del sujeto como un individuo social. Elster consideró el problema de que todo lo que no puede ser explicado se debe a la naturaleza compleja y cambiante del individuo. Para ello utilizó el individualismo metodológico en el sentido de que toda explicación de los fenómenos puede ser entendida y generalizable, con excepción del individuo. Sus acciones, sus relaciones y su naturaleza se encuentran en el fondo de la explicación de por qué las leyes económicas (de racionalidad) no son inmutables. El individuo elige de acuerdo con sus creencias, deseos y relaciones que motivan sus acciones y sus elecciones.

En su interés de explicar la conducta de los sujetos, Elster (1984) trabajó con la teoría de juegos porque ésta es, en sí misma, la manera en que se encuentran equilibrios sub-óptimos precisamente cuando se rompen los supuestos básicos de economía, y principalmente el axioma de racionalidad generado por problemas de información.

En este orden de ideas, tanto Weber como Elster consideran que los medios, las convicciones, lo emocional, los hábitos, las costumbres y creencias son elementos que los individuos toman en cuenta en sus elecciones. Los tipos ideales de Weber son el resultado de a lo que cada individuo da significado, acorde con su experiencia, su referencia hecha a partir de su historia de vida. Weber reconoce que los individuos mantienen implícitamente la noción de un "tipo ideal", la cual es una estructura armada que les brinda una referencia. Esta concepción coincide con Elster, quien manifiesta la forma de elegir mediante una estrategia individual que es el "juego" acorde 
con la información de que dispone, sus creencias, medios y valores. El punto de convergencia de ambos es la construcción de la propia realidad a partir de sus vivencias cotidianas y el reconocimiento de que se trata de una racionalidad limitada.

Weber ubica la limitación de la racionalidad en planos diferentes, por un lado en la acción - elección en nuestro caso - adaptada a los medios y fines, y por otra parte en la acción acorde con los valores. $\mathrm{El}$ aporte de Elster en este sentido es que brinda la posibilidad de develar la inclinación de la elección del individuo reconociendo la falta de información completa en la elección mediante la ejecución del juego. El proceso de elección de carrera se complementa con la postura de Elster, en virtud de que si bien los individuos eligen a partir de sus creencias, deseos y percepciones, también tienen referencias de una expectativa (de la carrera que eligen).

En nuestro caso de estudio, las percepciones sociales de una profesión se asumen equivalentes al "imaginario social" que da forma a un tipo ideal weberiano, y este tipo ideal se refleja posteriormente en el perfil de egreso de la carrera. Este perfil está compuesto no sólo por la visión personal de cada individuo, sino también por el imaginario social que entiende de una forma muy particular el papel del profesional del turismo, y por la experiencia de otros profesionales del turismo que reproducen un mismo conocimiento y generan una referencia arquetípica plasmada en una normatividad particular como lo es el plan de estudios de esta carrera. ${ }^{2}$

Para Weber el problema de información - considerado enfáticamente por Elster - es también fundamental y, aunque no refiera en su obra la teoría de juegos, su esquema metodológico considera que a mayor información mayor capacidad de una elección racional cada vez más completa. Por ejemplo, en la actualidad el tipo ideal puede ser una aproximación al perfil de egreso del profesional del turismo que se difunde por diferentes medios, de tal forma los aspirantes pueden darse cuenta que existe un perfil de ingreso y egreso porque hay información al respecto, aunque no se garantice que esta sea completa, simétrica y cierta.

Se entiende que este arquetipo del profesional del turismo surge del pasado y el ideal está en el futuro, plasmado en un perfil de egreso, en un plan de estudios. Si los arquetipos resurgen continuamente por obra de la memoria, y los ideales por la imaginación, los símbolos encierran un significado que exige ser descifrado (Dri, 1980). El arquetipo del profesional del turismo nace como un personaje que brinda servicios relacionados con la hospitalidad y los alimentos en un contexto particular desde que se manifiestan las necesidades del hombre por viajar. Reconocemos que la elección de carrera implica una serie de expectativas y consideraciones para el ingreso, pero también implica un pensar en el ser y el saber hacer dentro del mercado laboral futuro en un proyecto de vida.

Como se mencionó anteriormente, Elster (2010) manifiesta que las elecciones de los sujetos no siempre obedecen a una racionalidad absoluta y tienen información incompleta. En este sentido, el individuo es incapaz de comparar y catalogar las diferentes profesiones existentes por no poder realizar una conjugación entre las pruebas, creencias y deseos de una trayectoria profesional que le brinde un estilo de vida acorde con sus expectativas. Por lo tanto el individuo asigna probabilidades subjetivas a sus decisiones aunque no por ello sean irracionales en sentido absoluto, sino limitados en términos de opciones de información. En palabras de Elster:

A veces el proceso de ajuste acontece antes de la elección para eludir el desagradable estado mental

\footnotetext{
${ }^{2}$ El imaginario social es una producción constante que se genera a través del tiempo en los espacios donde existe socialización, y esta producción se traduce en símbolos, imágenes, formas y maneras de ver "algo" para que el colectivo lo convierta en real y aceptado racionalmente (Castoriadis, 2008: 5).
} 
asociado con una carrera reñida entre dos opciones. Se ha sugerido en tales casos que uno busca inconscientemente un marco dentro del cual una opción sea cual fuere tiene una clara ventaja sobre las demás, y que, una vez hallado dicho marco, uno la adopta momentáneamente y escoge la opción que le favorece (Elster, 1999: 56).

El problema de la elección ante información limitada es tratado vastamente por la literatura de teoría de juegos. Los agentes que tratan de establecer decisiones racionales se ven acotados no por un problema de racionalidad per se, sino por la incapacidad de obtener información completa, cierta y simétrica (Gibbons, 1992). Bajo esta consideración, la elección profesional se convierte en un proceso donde los individuos mantienen cierto nivel de ignorancia sobre la gestión conveniente de una profesión. De tal manera, y de acuerdo con las narrativas que se presentan, existen varias alternativas de resolución ante los problemas de información incompleta, incierta y asimétrica que se establecen al momento de elegir una carrera profesional. Estas alternativas o mecanismos de solución del problema de elección bajo incertidumbre se denominan "juegos" y básicamente son formas que permiten hacer elecciones bajo contextos de incertidumbre. Existen tres juegos básicos de resolución: selección adversa, señalamiento y punto focal (Gibbons, 1992).

Cuando los agentes tienen problemas de información limitada pueden optar por generar un proceso de selección adversa. En este caso la elección profesional se basará en el criterio de la opción que represente menor riesgo y mayor certidumbre aunque no represente la opción óptima. La elección profesional en este caso se basa en el criterio de la elección ante la opción menos alejada al esquema de preferencia deseable. Es este esquema de preferencia deseable una referencia de "tipo ideal" según la perspectiva de Weber.

Por otra parte, el señalamiento es un juego en el que la elección profesional se genera a partir de un conjunto de pautas de elección en función de la información reconocida y aceptada como verdadera que la profesión manifieste. En este sentido, la elección profesional se basará en la reputación que exista dentro de las opciones profesionales. Aquí, desde el punto de vista de Elster, el proceso cognitivo de creación de deseos y creencias se da a partir de la entrada de las creencias y deseos de los otros, ya que el señalamiento es un indicativo de la mejor opción, y se transmite como tal a la estructura psicológica del individuo que elige. De la misma manera, este carácter extremo del impacto de otras creencias y deseos es un aspecto que Weber plantea como el impacto del contexto macro al momento de la elección. Porque si bien la elección profesional por señalamiento es un proceso psicológicamente individual, el señalamiento es de orden macro.

Finalmente, el punto focal nos refiere el imaginario social que la profesión tiene. En este sentido, la elección profesional bajo este juego se da cuando el individuo elige bajo un contexto donde el imaginario social ha categorizado, jerarquizado o estigmatizado a ciertas profesiones, y el individuo elige bajo estos criterios. Es, desde el punto de vista de Weber, una "especie" de tipo ideal armado dentro del imaginario social.

Aunado al problema de información incompleta, incierta y asimétrica, existe incidencia por parte de otros factores en la elección, como puede ser que la naturaleza psicológica del individuo determine o incida fuertemente en una elección (visión concordante con Freud (2006) al considerar el inconsciente como el producto de la naturaleza psicológica del individuo). Akerlof y Kranton (2002 y 2010) han desarrollado una vasta literatura sobre educación e identidad (que en el caso de Akerlof y Kranton es un proxy de la naturaleza psicológica del individuo) en la decisión económica de elección en términos de la educación como retorno y muestran factores como la pertenencia a un grupo social, la naturaleza propia del individuo y la interacción con otros agentes 
de diversa o similar naturaleza, que inciden en sus elecciones educativas. Por otra parte Akerlof (1983) habla también de los filtros de lealtad, que son una forma de distorsión de la información que los agentes asumen en aras de mantener cierta lealtad a un conjunto de principios propios de contextos familiares y de grupo. Sin embargo, no profundizaremos en el aspecto de la identidad del individuo ya que esto va más allá del objetivo de esta investigación.

\section{Estrategia metodológica para el caso de la elección de la carrera de turismo}

En el trabajo de campo que refiere este artículo, se trata de indagar si los entrevistados mantienen un supuesto básico de tipo ideal formado no sólo de sus propias percepciones, sino también de las percepciones sociales de lo que es un profesional del turismo. La composición de esta plataforma metodológica obedece a una lógica de interacción entre actores sociales. A partir de una metodología cualitativa, utilizamos la técnica de Relatos de Vida (RV) de acuerdo con Bertaux (2005), acotándola a un tema central: el motivo de la elección de carrera para el caso de la Universidad de Guadalajara. ${ }^{3}$
Sin embargo, tenemos que hacer un apunte metodológico importante. Nuestra revisión de las narrativas en los RV se circunscriben a lo que mencionan De Gaulejac, Rodríguez Márquez y Tarecena Ruiz (2005) sobre la ruptura epistemológica entre Freud y Bourdieu, donde el primero pone a la psicología por delante del análisis sociológico aduciendo que en el subconsciente reposa el entramado social en que se mueve el individuo. Por otra parte, Bourdieu considera los contextos sociales como determinantes principales del accionar individual. En este trabajo no pretendemos resolver esta ruptura, sin embargo reconocemos la importancia de mencionar ambas lógicas para tener una visión más amplia sobre el problema de la elección de carrera, que es afectado tanto por un entorno social fuerte como por un proceso de creación individual psicológico.

A partir de la categoría de análisis "elección de carrera" y la dimensión de "género" se develan las motivaciones, circunstancias y condiciones que incidieron en la elección (tabla 1), esto nos da pauta para conjugar diacrónica y sincrónicamente el análisis de la elección profesional (Dubar, 2002).

Tabla 1. Categoría de Análisis: Elección de la profesión

\begin{tabular}{|c|c|c|c|}
\hline Categoría & Indicador & Preguntas clave & Significado \\
\hline Elección de la profesión & $\begin{array}{l}\text { Vivencias que impactaron a los } \\
\text { entrevistados en la elección de } \\
\text { carrera }\end{array}$ & \multirow{2}{*}{$\begin{array}{l}\text { ¿Por qué decide estudiar turismo? } \\
\text { ¿De dónde es originario? } \\
\text { ¿Cómo se enteró de la existencia de } \\
\text { la carrera? } \\
\text { ¿Existió en su momento alguna } \\
\text { influencia para elegir la carrera de } \\
\text { turismo? }\end{array}$} & \multirow{2}{*}{ El motivo de la acción } \\
\hline Dimensión de la categoría: género & $\begin{array}{l}\text { Percibir la presencia o ausencia } \\
\text { de figuras que impactan en sus } \\
\text { decisiones. }\end{array}$ & & \\
\hline
\end{tabular}

Fuente: elaboración propia.

\footnotetext{
${ }^{3}$ El resultado que se presenta en este trabajo es parte de una investigación más amplia donde se hace el ejercicio de relato de vida completo, aquí sólo presentamos una categoría de análisis: elección de carrera.
} 
El trabajo de campo se desarrolló en la institución educativa (UdeG) durante el periodo de enero a junio de 2013, con nueve académicos egresados de la licenciatura en Turismo (cuatro hombres y cinco mujeres), con antigüedad en la docencia entre 15 y 35 años, y quienes estuvieron involucrados en alguna modificación del plan de estudios de la propia licenciatura. En este sentido, nos apoyamos en la postura de Galindo (1994) en términos de objetividad-subjetividad como referente en este acercamiento al campo. La objetividad que implica el proceso de distanciamiento necesario del fenómeno para poder analizarlo separado de nuestra propia historia y conceptos.

Como consideración metodológica básica identificamos a nuestros informantes con seudónimos: Gerardo, Aranza, Raúl, Mauricio y María quienes tienen mayor antigüedad en la institución; a su vez, tenemos a Constanza, Socorro, Fulián y Mariana con menor antigüedad.

Así pues, las narrativas nos fueron desplegando una línea cronológica de hechos, situaciones, vivencias y que develan el sentido como sustento de sus propias experiencias, pero también nos muestran una trama compleja que nos ha permitido mirar más allá de la historia singular del sujeto y avanzar en dimensiones que no se pueden comprender fuera de un marco multidimensional que les tocó vivir.

Por lo anterior, en la siguiente sección se presenta el marco de organización temática del análisis hacia la interpretación, pero también tiene la intención de hacer un orden interpretativo del proceso de la elección de carrera, pudiendo distinguir dos grupos de profesores de acuerdo con el contexto e información existente sobre la época en que decidieron su profesión y posteriormente se desarrollaron: un primer grupo es el de aquellos que realizaron una elección y estudios durante la década de los setenta: los fundadores, y el segundo grupo durante la década de los ochenta: los herederos.

\section{La década de los setenta: los fundadores}

El primer paso es dar una visión del contexto del país para ajustar el marco en que se desarrolla nuestro problema de investigación. Si damos una mirada al contexto del país en la década de los setenta, se da entonces el cierre del proceso de sustitución de importaciones, México cae en una fuerte crisis de deuda debido al agotamiento del modelo y existe una transición de una economía cerrada a la de una economía abierta. El advenimiento del neoliberalismo y del proceso de crecimiento exportador transforma la economía mundial en una economía altamente globalizada e interconectada en todos sus procesos productivos y de servicios (Villareal, 1997).

Los fuertes excedentes petroleros en México y el clima de globalización emergente en el mundo favorecieron el dinamismo del turismo debido a las mínimas barreras proteccionistas, principalmente al brindar incentivos para la inversión extranjera directa para la construcción de grandes cadenas hoteleras en los principales centros turísticos. Desde la perspectiva del discurso político en materia de turismo, éste se apreciaba en toda América Latina como un motor de desarrollo (De Kadt, 1979). Además, también se identifica la influencia ideológica del neoliberalismo en la educación superior en México.

Así, a partir del emergente modelo neoliberal en el mundo, se suponen nuevas formas de regulación política y social que implican un llamado a nuevos mecanismos de adaptación y a una dinámica global cada vez más compleja y con necesidad de diferenciar actividades que corresponden a nuevas formas de organización del trabajo. En México la economía no se abría aún, pero el excedente petrolero incrementó la capacidad de infraestructura turística que respondía a una creciente demanda internacional (De Kadt, 1979). ${ }^{4}$

${ }^{4}$ De acuerdo con De Kadt (1979) un ejemplo de este proceso fue el desarrollo de Zihuatanejo como centro turístico en 1971. 
En este contexto, las narrativas de nuestros sujetos que estudiaron turismo nos invitan a pensar que la elección de carrera carece de un ideal de identificarse con un grupo al que le corresponden ciertas tareas que corresponden a un "ser y hacer" en el mercado laboral, que no es estático. En este sentido, la elección de carrera obedece a una amplia gama de factores externos e internos, que van desde las condiciones de mercado hasta las consideraciones personales y familiares.

Ante la pregunta $i$ Por qué decide estudiar turismo?, los entrevistados masculinos que cursaron la carrera a principio de la década de los setenta, viven de manera diferente la apreciación de su elección comparada con la apreciación de las mujeres, porque las diferencias se encuentran en relación con las condiciones sociales de existencia, que colocaban al hombre y a la mujer ante necesidades y posibilidades muy diversas; asimismo, se encuentran relacionadas con lo que cada quien espera no de la profesión sino del trabajo inmediato.

El género juega un papel fundamental en la elección de carrera, sobre todo en la década de los setenta, ya que la categorización social de una profesión puede ser fuertemente impactada por el género que se percibe en el imaginario social que le pertenece por naturaleza. No se han demostrado diferencias en las capacidades individuales, pero el estereotipo de ser hombre o mujer es condicionado de la acción social desde antaño, y lo podemos identificar incluso en el vestido de las mujeres que llega a demostrar que quien lo usa se abstenía de toda tarea productiva (Veblen, 1974: 177).

\section{El género y la elección}

A partir del origen de esta profesión moderna, desde un enfoque weberiano, hemos visto que existe una diferencia en las motivaciones para la elección de carrera de acuerdo con el género. Por una parte, los hombres eligen su carrera de acuerdo con una acción racional con arreglo a fines, mientras que la mujer realiza su elección por una acción racional con arreglo a valores, o como una acción tradicional. Claro está que evitando una visión reduccionista, podemos conceder el hecho de que no existen acciones puras, sino que en parte tanto el género masculino como el femenino se permiten tener elección de carrera a partir de otras motivaciones.

En el caso de los hombres, la elección de carrera se ve influenciada por las necesidades y requerimientos económicos. Nuestros informantes nos comparten la intención de estudiar otra profesión, como medicina o veterinaria, sin embargo por cuestión económica, "tenía que trabajar y estudiar", optan por su segunda opción, que es "Turismo". Aunado a esto, la decisión no sólo se ve determinada por sus requerimientos económicos sino también por su actividad previa; no sólo se habla de la experiencia sino de cierta lealtad a una actividad que les genera confianza.

En este orden, el trabajo para el hombre constituye una actividad importante tanto en el momento de su elección como durante su permanencia en la formación académica, porque le permitía la subsistencia personal y familiar; en la mayoría de los casos, el manejo de un oficio relacionado con los servicios turísticos antes de ingresar a la carrera, les permitió de alguna manera descubrir nuevas capacidades que les impulsaron en su elección profesional, tal es el caso de Raúl:

Antes de ingresar a la carrera estuve al sur de San Francisco [Estados Unidos], ahí duré cinco años trabajando en todo, trabajando siempre con italianos; en los campos en las 'piscas', después estuve en fruterías y luego me fui a un restaurant de lavaplatos y luego terminé de cocinero, empecé a cubrir los descansos de los cocineros y del chef.

Gerardo, además de coincidir en estar involucrado tiempo antes con el sector servicios, nos menciona porqué decidió estudiar turismo: 
porque yo trabajaba en el ramo de alimentos y bebidas, y a la edad de 18 años ya era gerente de restaurante, trabajé desde que tenía 12 años en muchos restaurantes porque mi mamá era cocinera en un restaurante.

En estos casos, los informantes no manifestaron un gusto desmedido por su carrera, pero se encuentran satisfechos con su elección y con el ejercercicio posterior de la profesión. De esto podemos considerar dos cosas: primero, esta profesión les reditúa lo necesario para sus expectativas económicas y de vida a partir de una experiencia previa que garantiza un nivel de subsistencia. Segundo, el gusto expresado por su actividad previa establece 7, según Akerlof (1983), un "filtro de lealtad" que puede ejercer una poderosa influencia sobre su elección y sus interacciones con los otros con quienes se desenvuelve, tomando forma de una elección profesional, porque de acuerdo con Weber el oficio se materializa en una profesión en la búsqueda de dominar un saber.

En este sentido, este filtro de lealtad es una manifestación de deseos y creencias en que se apoya el individuo al momento de su elección profesional. De acuerdo con Elster (1984), el proceso de precepción psicológica del individuo se apoya en el filtro de lealtad, que forma un elemento importante en la conjugación de sus probabilidades en la manifestación de un "juego", porque para Elster el filtro de lealtad es una manera de subsanar el problema de la información incompleta.

Por parte de Weber, el filtro de lealtad funciona como una "especie" de referencia de tipo ideal implícita en los procesos de decisión de los individuos. Este filtro de lealtad introduce dentro del proceso de elección un elemento de influencia dentro del esquema de racionalidad limitada que descarga al individuo de responsabilidad completa de las decisiones a tomar. ${ }^{5}$ En el caso del profesional del turismo, ante la ausencia de un referente profesional se presenta en las entrevistas el oficio o la actividad laboral previa como una referencia.

En este orden, a mediados de la década de los setenta, que suponían nuevas formas de producción y organización del trabajo, la carrera aún no era muy demandada y cualquiera que quisiera estudiarla tenía su lugar asegurado, como bien nos lo expresa Raúl, quien en su imaginario estaba primero ser médico, pero como lo mencionamos antes, siguiendo ese filtro de lealtad ante sus experiencias previas en el área restaurantera, comenta su situación:

En el 75, circulando en Guadalajara, pasé por turismo y dije: ¡Ahhi ¿por qué no? Entonces llegué [a la facultad] y pregunté, ¿Qué necesito para entrar a turismo?... [me dicen] ¿ya terminó la prepa?...contesté 'Sí'... 'Pues ánimo porque aquí lo que queremos son estudiantes' y pues entré a Turismo en 1975.

En la lógica femenina no era distinto, este es el caso de Aranza, quien ingresa en 1976:

Todos los que hacíamos solicitud entrábamos... [a la carrera], por eso me sorprendí tanto cuando mi sobrina (que entró en 1983) me dice: ¡felicítame tía que sí salí en listas!, iquedaron rechazados tantos! sólo entramos 120 —¿Qué? ¡ no lo podía creer.

En el caso de nuestros informantes no se aprecia una visión clara de lo que significaba la profesión del turismo al momento de elegir su carrera profesional - mediados de la década de los setenta-, la elección por turismo también se relaciona con la movilidad, háblese de espacios laborales o geográficos, al respecto Aranza relata: "eran bastantes campos de acción y sobre todo me llamó la atención que podías

\footnotetext{
${ }^{5}$ Un ejemplo claro es cuando un individuo decide estudiar derecho porque su padre y/o sus hermanos estudiaron derecho y son una fuente de presión-inspiración para decantarse por estudiar esta profesión.
} 
ir a trabajar a otros lugares, que tu carrera te podía ayudar a abrir puertas en otros lugares".

La elección profesional lleva implícita una caracterización de "que quiere ser y para qué"; con estas interrogantes nos damos cuenta en las narrativas que se van resolviendo al paso de sus relaciones con otros en sus diferentes ámbitos tanto familiares como laborales y de amistades. Asimismo, de las narrativas se puede comprender que la elección hace patente la importancia de la posibilidad de realizar otras actividades laborales mientras estudiaban. Parece, como resultado de las entrevistas, que la elección de carrera dependió de la flexibilidad de la misma, ya que los entrevistados trabajaban y estudiaban, y era casi un requisito que la carrera les permitiera esta doble función.

Aunado a lo anterior, y con fuerte ascendencia en el género femenino más que en el masculino, la influencia de familiares o amigos también puede influir en el caso de la elección de carrera como bien lo describe Socorro una de nuestras informantes:

Mi padre era militar y desde que yo recuerdo de niña cuando se escuchaba por la radio y la televisión de las Olimpiadas del 68, me decía que el turismo era muy importante para la economía del país y que era una carrera para mujeres.

Ciertamente, desde fines de los sesenta y principios de los setenta, con la influencia del movimiento feminista en Estados Unidos y Europa, aparecen los estudios teóricos sobre el trabajo remunerado y no remunerado que realizan las mujeres, y así el trabajo femenino es relacionado con los servicios, háblese del comercio o la enseñanza (Rendón, 2008: 21), lo que provoca un incremento considerable de mujeres en las universidades a partir de los setenta, principalmente en profesiones que tienen que ver con las ciencias humanísticas.

Como referimos anteriormente, el género, en términos de recursos materiales y simbólicos, pone de manifiesto que para el masculino el trabajo y por ende la búsqueda de una profesión es un referente de su propia construcción (con arreglo a fines). Sin embargo, para el caso del género femenino esta manifestación es con arreglo a valores, y su búsqueda profesional significa autonomía e independencia personal. En este orden, la mujer deja ver su capacidad de agencia de acuerdo con sus recursos culturales, económicos y relacionales. ${ }^{6}$ Parte de esta capacidad de agencia es que existe una percepción social en general, y familiar en particular, del rol femenino en el desempeño profesional. Por ejemplo el siguiente comentario de Aranza:

\section{[legaban de Nayarit] aquí en Guadalajara [... mi papá] nos puso a terminar la primaria y a mi hermana a estudiar corte y confección. Cuando terminamos [ambas] la primaria, mi papá dijo: us- tedes no van para trabajar, ustedes van para que las mantengan.}

Esta narrativa denota que la percepción familiar del papel de la mujer - finales de la de la década de los años sesenta - no era la de ser una profesional productiva de tiempo completo, bajo la visión de una profesión universitaria, sino sólo como una actividad de tiempo parcial para el sustento y apoyo de una vida familiar integrada. Sin embargo, la necesidad como un factor económico cambia la perspectiva familiar y se orienta la vocación que en el corto plazo puede generar mayores ingresos. Al respecto Aranza

\footnotetext{
${ }^{6}$ El trabajo de Ayalon (2003) trata de explicar el proceso de selección de la carrera en el nivel de educación superior considerando el género como una de las principales variables explicativas para resaltar las diferentes habilidades que poseen tanto hombres y mujeres; en su estudio realiza una muestreo de 6139 aspirantes a la universidad Tel Aviv en Israel, en un modelo matemático, destaca que las mujeres evitan cursos avanzados de matemáticas en high school porque consideran que son irrelevantes para su formación profesional.
} 
rescata: "Mi papá tuvo crisis económica y entonces a mi hermana la más grande que ya trabajaba le pagó los estudios de secretaria ejecutiva contable".

Bajo esta misma lógica familiar, dicho en términos de la teoría de Juegos, la elección no representa un punto focal sino como comparsa de otras actividades productivas y profesionales, ad hoc con una vida familiar. En el caso del turismo, podemos decir que de acuerdo con la naturaleza de su creación, es una profesión más identificada con el género femenino, esto también confirma la demanda natural que se ha venido dando desde la creación de la profesión. ${ }^{7}$

En este sentido, podemos decir que la elección profesional tiene un componente de género determinante en su construcción. Como mencionan Akerlof y Kranton (2010: 716), la internalización de las normas se manifiesta de diferente manera según el género, y éste a su vez implica el desarrollo de puestos de trabajo con perfiles específicos, con géneros implícitos al interior.

Por lo anterior, resultó pertinente hacer una distinción entre quienes eligen su carrera en la década de los setenta y quienes lo hacen en los ochenta, en virtud de que supone reconocer que están moldeados por y en contextos distintos, y conformados desde diferentes ámbitos y en constante transformación a lo largo de la vida de los sujetos. Es importante resaltar esta división porque la característica de género que hemos estado tratando hasta ahora se diluye en la década de los ochenta, por tanto ya no es relevante, en términos de análisis, destacar esta diferencia. Las entrevistas destacan que ahora se cuenta con mayor información.

\section{La década de los ochenta: los herederos}

A principios de la década de los ochenta se vivió un viraje total en el desempeño económico nacional. Pasamos de la llamada "administración de la abundancia” del periodo de López Portillo, al sexenio de crecimiento cero con Miguel de la Madrid. En esta década, sobre todo en su primera parte, se tuvieron profundas crisis económicas, iniciando con la crisis petrolera y la del tipo de cambio, para seguir con una crisis de la bolsa de valores y eventos planeados como un mundial de futbol, además de siniestros como el terremoto de 1985.

Las condiciones económicas del país fueron precarias y la convulsión social se dejó sentir fuertemente en un conjunto de protestas y surgimientos de espacios políticos inéditos. El desempleo aumentó dramáticamente y la inversión extranjera dejó de fluir (Villareal, 1997). Las actividades profesionales fueron severamente castigadas y la visión de la elección profesional fue enmarcada en un conjunto de crisis que iban desde las devaluaciones insospechadas hasta el desánimo por la corrupción.

La actividad comercial descendió rápidamente y el flujo turístico decayó sobre todo a nivel nacional. La crisis económica, política y social puso en marcha un conjunto de estrategias "modernizadoras" a finales de los ochenta con privatizaciones masivas, aperturas comerciales y la bienvenida a un modelo de economía liberal que transformaba la visión de elección profesional. Indudablemente se hacía notar más la actividad turística y había un interés por la planeación en todos sus sentidos, en este orden, se incluyó un plan de capacitación turística para brindar impulso a los atractivos turísticos del país y a la oferta hotelera.

Resultó entonces notorio un cambio de perspectiva respecto a los sujetos que eligen la carrera en la década de los ochenta, en tanto se percibe más conocimiento de la existencia de la carrera, como lo expresan nuestros informantes, y donde las características y personalidades de los individuos, sus actividades preferidas, sus competencias, su estilo de vida

\footnotetext{
${ }^{7}$ Actualmente la proporción de hombres que estudian la carrera de turismo oscila en el $30 \%$, prevaleciendo el $70 \%$ del género femenino, según datos de la actual coordinadora de la licenciatura en Turismo del CUCEA, UdeG.
} 
determinan la elección profesional. Tenemos individuos con mayor información y conocimiento para establecerse en ambientes laborales definidos, de acuerdo con un estereotipo ocupacional. Es el caso de Julián, que nos comenta:

Yo desde que estaba en la prepa tenía la inquietud de dedicarme a las ciencias sociales. Y tenía la intención de estudiar la carrera de derecho. Pero en la orientación vocacional que me dieron en la prepa me explicaron muy bien sobre los perfiles de las carreras y me gustó la licenciatura en turismo, además yo soy de Sinaloa y allá en Mazatlán, pues dije; debe haber pues, mucho campo de acción.

Constanza, por su parte, refleja su gusto por la carrera por una experiencia de la cotidianidad que además también hace alusión a un filtro de lealtad como una manifestación de su rol profesional y familiar, que deja ver esta característica que influye en su decisión de estudiar la carrera:

\begin{abstract}
Mi hermana ya estudiaba turismo $[\ldots y$ y siempre me imaginé trabajando en hoteles [...] Te dará risa pero había una serie de televisión llamada 'Hotel' y me encantaba, seguro que influyó para que yo quisiera trabajar en un hotel.
\end{abstract}

Socorro, reconociendo la influencia de su padre para estudiar una carrera para "mujeres", reconoce su elección por la carrera: "yo entre con la idea de viajar".

En esta década de los ochenta la carrera ya tenía más de diez años en funcionamiento, y la demanda hacia la carrera iba en aumento. Por tanto, la decisión de estudiar turismo se enfocó en las actividades de servicios, en la hospitalidad que esta profesión implicaba. Los sujetos mostraron sentirse identificados por esta profesión independientemente de su alto o bajo reconocimiento social. Aquí podemos decir que, desde el enfoque de Weber, las elecciones racionales en la elección profesional para ambos géneros obedece definitivamente a una acción racional con arreglo a fines. Debido al aumento de información y la reforma curricular emprendida en la carrera de turismo, en esta década se establece ya un "tipo ideal" de referencia dentro del perfil de egreso que es difundida a los interesados por esta carrera.

En nuestros informantes se aprecia una intención de búsqueda que no necesariamente tiene que ver con el "ser" un profesional del turismo sino más bien con "el hacer", es como una búsqueda de su propia vocación que nos denota una ausencia de imagen de lo que es un profesional del turismo, pero una claridad en el "hacer" dentro del sector servicios.

Desde el punto de vista de Elster, la incertidumbre que está inscrita dentro del proceso de elección profesional se ha reducido por la existencia de información, lo cual no implica que exista una racionalidad completa en la elección de carrera, ya que no hay certidumbre de lograr las expectativas profesionales formuladas inicialmente, debido a que la profesión en sí misma no manifiesta reconocimiento social fuera del ámbito de los servicios. La incertidumbre por lo tanto proviene de esta falta de información para construir en el imaginario la participación en la planeación turística.

El equilibrio en la elección profesional se genera a partir de probar los deseos y las creencias que nos mueven a la acción. En nuestro caso la elección de una profesión tiene que concatenar adecuadamente estos deseos y creencias a un conjunto de pruebas dadas por una información que se perfecciona en el señalamiento (aunque estas pruebas no son óptimas), debido a una mejora en los procesos de reforma institucional.

El conjunto de medios, creencias, valores y deseos convergen de mejor manera al existir mayor información sobre el proceso de decisión, ya que el mecanismo de señalamiento se perfecciona y da mejores pautas de elección a los individuos por los "haceres" más que por el "ser" del profesional, lo que nos lleva 
a comprender que el proceso de elección tiene un elemento de fallo de racionalidad, y la precepción individual sigue siendo el elemento definitorio al momento de elegir.

\section{Conclusiones}

En este trabajo se desarrolla un análisis comprensivo sobre la elección de carrera en Turismo fundada en 1968 por la UdeG, donde se identifica la elección racional desde la perspectiva teórica de Max Weber y Jon Elster. Ambos comparten la idea de que existe una racionalidad limitada en la elección de los individuos. El individuo genera una serie de conjeturas y estrategias que le permiten elegir su mejor opción.

Se realizaron un conjunto de entrevistas a miembros de las primeras generaciones de egresados de la Universidad de Guadalajara - actualmente docentes/académicos-, bajo una categoría de análisis: la elección de carrera. La narrativa misma nos remitió a mecanismos sociales que influyeron en la experiencia individual, y que implicaron el sedimento para encontrar el motivo de su elección vista como una acción social. Esto nos permitió hacer un análisis de cómo eligieron la carrera de turismo a partir de sus motivaciones principales. Nuestros hallazgos nos permitieron establecer relaciones y diferencias en consideración con la literatura revisada para el entendimiento de la elección de carrera enfatizando diferencias temporales y de género.

En la década de los setenta, podemos decir que las mujeres eligieron su profesión basándose en una elección racional con arreglo a valores, fundamentada en sus convicciones según mandatos y exigencias de la misma sociedad. Por parte de los hombres, su decisión se aprecia como una elección racional con arreglo a fines porque concibe claramente el fin de la profesión y elige en consonancia con los medios, al materializar un oficio en una profesión para perfeccionar un saber.

Así, desde la perspectiva teórica de Elster, ante la ausencia de información de esta profesión en los setentas, el sujeto asigna probabilidades para elegir con base en el manejo de un oficio que tiene que ver con el sector de los servicios turísticos, haciendo énfasis en filtros de lealtad. Éste es un ejemplo de cómo los individuos pueden resolver sus elecciones con base en juegos donde consideran sus creencias, deseos y valores, y generan su propia información a partir de un contexto macro en el que viven. El individualismo metodológico de Elster se identifica en cada sujeto al elaborar su propio juego en la elección con sus procesos cognitivos.

Acorde con los tipos de juegos, el punto focal se presenta en las narrativas con la característica del género, y es como una decisión basada en una búsqueda de legitimidad tradicional, que obedece a respuestas de hábitos de una comunidad, manifestándose sus representaciones culturales históricamente asumidas en una profesión femenina para servir al otro.

En la década de los ochenta cambia la perspectiva de la profesión porque se gesta un conjunto de reformas al interior y exterior de la institución que contextualiza tanto la actividad turística como la instrucción profesional en México, y en particular la profesión del turismo: los egresados se convierten en docentes. Existe una mayor información de la profesión y los procesos de decisión mantienen un elemento de mayor certidumbre con énfasis en los servicios turísticos.

En las entrevistas podemos detectar que el atributo de género se diluye. Ahora los individuos deciden bajo condiciones más favorables (aunque no óptimas) pero carentes de una referencia en el "ser" del profesional por lo que las decisiones se hacen con arreglo a fines para ambos géneros.

Desde el punto de vista weberiano, la información permite tener referencias sobre las cuales toman una decisión, se plantean institucionalmente "tipos ideales" que reflejan en gran medida las capacidades y los "haceres" en un perfil de egreso, más que definir una identidad del profesional. Los individuos tienen una experiencia previa que determina tanto el gusto 
como las expectativas laborales al elegir la profesión del turismo.

Desde el punto de vista de Elster, en la década de los ochenta existe mayor información que elimina la incertidumbre acerca del "hacer" del profesional del turismo, pero no deja de lado el problema principal al momento de una elección racional. Porque para Elster el individuo sigue haciendo decisiones basadas en creencias y deseos al no existir una referencia que permita situar al profesional del turismo con el "ser", los "haceres" no son suficientes para tener certidumbre, ya que las actividades del sector turístico no son exclusividad del profesional del turismo. Como una reflexión final encontramos en este trabajo la riqueza de combinar la visión micro-macro propia de los cuerpos teóricos de Weber y Elster donde para ambos la acción social parte de hechos individuales de la vida cotidiana y la irracionalidad se manifiesta en la elección del sujeto al no tener claras sus propias conexiones de sentido. Así se complementan en la explicación del caso de la elección de carrera del profesional del turismo, ya que es en sí mismo un proceso que discurre en el interior del individuo y el contexto en el cual se desarrolla y se relaciona.

Lo anterior es relevante para la profesión del turismo, ya que a pesar de la importancia económica y social de la actividad turística, esta profesión presenta problemas severos de información acerca de su "ser" y "haceres". La elección de la carrera de turismo se convierte en una temática fundamental de estudio, lo que nos llevaría a indagar en futuros trabajos sobre problemas de abandono escolar provocada por una "mala" elección y el esclarecimiento del "ser" mediante la propia identidad del profesional del turismo. 


\section{Referencias}

Akerlof, George (1983), "Loyalty filters", The American Economic Reviere, vol. 73, núm. 1, pp. 54-63. <http://www. jstor.org/stable/1803926> [Consulta: enero de 2013].

Akerlof, George y Rachel Kranton (2010), Economics and identity: how our identities shape our work, wages and wellbeing, Princeton, University Press.

Akerlof, George y Rachel Kranton (2002), "Identity and schooling: some lessons for the economics of education", Fournalof Economic Literature, vol.40, núm.4,pp. 1167-1201, <https://doi.org/10.1257/002205102762203585> [Consulta: enero de 2013].

ANUIES (2016), Anuarios estadísticos de educación superior, México, <http://www.anuies.mx/ informacion-y-servicios/informacion-estadistica-deeducacion-superior/anuario-estadistico-de-educacionsuperior> [Consulta: noviembre de 2017].

Ayalon, Hanna (2003), "Women and men go to university: mathematical background and gender differences in choice of field in higher education", Springer International Publishing, Nueva York, vol. 48, pp. 277-290.

Becker, Gary S. (1993), Human capital. A theoretical and empirical analysis, with special reference to education ( $3^{\mathrm{a}} \mathrm{ed}$.), Chicago, The University of Chicago Press.

Bertaux, Daniel (2005), Los relatos de vida, Barcelona, Ediciones Bellaterra.

Bordieu, P. (2007), El sentido práctico, Buenos Aires, Siglo XXI Editores.

Campos, Agustín (2014), Métodos mixtos de investigación. Integración de la investigación cuantitativa y la investigación cualitativa, México, Nueva editorial Iztaccihuatl.

Castoriadis, Cornelius (2008), "El pensamiento de Cornelius Castoriadis", vol. 2, Ediciones Proyecto Universitario.

Chavoya Peña, María Luisa (2003), "Diversidad y diferenciación en la educación superior en Jalisco", en Nueva Antropología, vol. 19, núm. 62. pp. 121-142.

Cleaves, Peter (1985), Las profesiones y el Estado: el caso de México, México, El Colegio de México.

De Gaulejac, Vincent, Susana Rodríguez y Elvia Taracena
(2005), Historia de vida: psicoanálisis y sociología clínica, México, Universidad Autónoma de Querétaro.

De Kadt, Emanuel (1979), Tourism. Passport to development, Washington, Oxford University Press.

Dri, Rubén (1980), "Identidad, memoria y utopía. Estado, legitimación y sentido", en Estudios de ciencias sociales, núm. 1, Buenos Aires, Secretaría Académica de la Universidad de Buenos Aires.

Dubar, Claude (2002), La crisis de las identidades, Barcelona, Ediciones Bellaterra.

Elster, Jon (2010), La explicación del comportamiento social: más tuercas y tornillos para las ciencias sociales, Barcelona, Gedisa.

Elster, Jon (1999), fuicios Salomónicos: Las limitaciones de la racionalidad como principio de decisión, Barcelona, Gedisa.

Elster, Jon (1984), "Marxismo, funcionalismo y teoría de juegos. Alegato en favor del individualismo metodológico", en Zona Abierta, núm. 33, pp. 21-62.

Freud, Sigmund (2006), El malestar en la cultura, Madrid, Alianza Editorial.

Galindo, Jesús (1994), Entre la exterioridad y la interioridad. Apuntes para una metodología cualitativa, Guadalajara, ITESO.

Gibbons, Robert (1992), Game Theory for Applied Economists, New Jersey, Princeton University Press.

Higuera Ojito, Víctor Hugo (2012), "Análisis económico de la demanda educativa en programas de Ciencias Económicas: un modelo de elección basado en un logit binomial", en Ad-Gnosis, vol. 2, núm. 2, pp. 13-21.

Jiménez, Juan de Dios y Manuel Salas (1999), Análisis económico de la elección de carrera universitaria. Un modelo logit binomial de demanda privada de educación, Valencia, Instituto Valenciano de Investigaciones Económicas, S.A. <http://web2011.ivie.es/downloads/docs/wpasec/ wpasec-1999-03.pdf> [Consulta: enero de 2013].

Lindon, Alicia (2004), "La huella de Lefebvre sobre la vida cotidiana”, en Revista Veredas, México, Universidad Autónoma Metropolitana, vol. 5, núm.8, pp. 39-60.

Rendón, Teresa (2008), Trabajo de hombres y trabajo 
de mujeres en el México del siglo XX, México, UNAM/ CRIM/PUEG.

Rodríguez, Armando y Lucía Tamez (2016), "Sector turismo, pilar de la economía mexicana", México, El economista, <https://www.eleconomista.com.mx/mercados/Sectorturismo-pilar-de-la-economia-mexicana-20161208-0082. html> [Consulta: noviembre de 2017].
Veblen, Thorstein (1974), Teoría de la clase ociosa, México, Fondo de Cultura Económica.

Villareal, René (1997), Industrialización, deuda y desequilibrio externo en México: Un enfoque neo estructuralista (1929-1997), Madrid, Fondo de Cultura Económica.

Weber, Max (2008), La ética protestante y el espiritu del capitalismo, Barcelona, Ediciones Península.

\section{Cómo citar este artículo:}

Cruz Barba, Evangelina (2019), "Elección de la carrera de Turismo: una mirada sociológica”, en Revista Iberoamericana de Educación Superior (RIES), México, UNAM-IISUE/Universia, vol. X, Núm. 28, pp. 170-185, DOI: HTTPS://DOI.ORG/10.22201/IISUE.20072872E.2019.28.435 [consulta: fecha de última consulta]. 